\title{
Improved-Node-Probability Method for Decision Making in Priority Determination of Village Development Proposed Program
}

\author{
Dedi Trisnawarman \\ Faculty of Information Technology \\ Universitas Tarumanagara, Jakarta, Indonesia \\ Department of Computer Science \& Electronics \\ Universitas Gadjah Mada \\ Yogyakarta, Indonesia
}

\section{Sri Hartati}

Department of Computer Science and Electronics, Faculty of Mathematics and Natural Sciences, Universitas Gadjah Mada, Yogyakarta, Indonesia

\author{
Edi Winarko \\ Department of Computer Science and Electronics, \\ Faculty of Mathematics and Natural Sciences, \\ Universitas Gadjah Mada, \\ Yogyakarta, Indonesia \\ Purwo Santoso \\ Department of Politics and Government \\ Faculty of Social and Political Sciences, \\ Universitas Gadjah Mada, Yogyakarta, Indonesia
}

\begin{abstract}
This research proposes a new method, the probability of nodes (NP) and the cumulative frequency of indicators within the framework of Bayesian networks to calculate the weight of participation. This method uses the PLSPM approach to examine the relationship structure of participatory factors and estimate latent variables. Data were collected using questionnaires involving participants offering proposals, the village residents themselves. The participation factors identified in this research were divided into two categories, namely, internal factors (abilities) and external factors (motivation). The internal factors included gender, age, education, occupation, and income, while the external factors included motivation relating to economic, political, sociocultural, norm-related, and knowledge-related issues. Moreover, there are three factors directly affecting the level of participation, they are: the level of attendance in meetings, participation in giving suggestions, and involvement in decision making. The test results showed that the application of participation weight in decision making priority of proposal of village development program give change of final rank of decision with test result as: recall $50 \%$, precision $80 \%$ and accuracy $50 \%$.
\end{abstract}

Keywords-Bayesian networks; PLS-PM; participation weight; decision making; village

\section{INTRODUCTION}

In the last decades, there has been an increasing interest among the community in decision making [1]. Community participation has become part of the various environments for the implementation of decisions made, such as in the sectors of government [2], integrated watershed management [3], [4] development in agriculture [5], environmental management [6] forest management [7], and planning [8].

The significance of participation is asserted by Conyers [9], who states that first, community participation is a tool to collect information about the conditions, needs, and attitudes of the local community, without which development programs and projects will end in failure; second, people tend to have a higher level of confidence in particular development projects or programs if they feel involved in the process of preparation and planning of such projects or programs as this makes them know more about the project and develop a sense of belonging towards the project; third, engaging the community in the development of their own community constitutes a right acknowledged in democracy.

Decision making relating to determination of proposed village development programs taking priority falls into the category of group decision-making. In the group decisionmaking, community participation can be seen in the process of proposing programs and making decisions. In fact, decisionmaking through participation does not work properly. This is because the role the government plays in the implementation remains centralistic with top-down planning, thus both the aspirations and the resulting proposals lack quality, decision making is dominated by the village elite, are regular annual routine, and cannot accommodate the needs of the community.

This research aims to identify factors affecting participation in village development program planning and quantify them in the form of participation scores. Then, those participation scores were used in decision making to determine the rank of the proposed development programs in order of priority.

\section{LITERATURE REVIEWS}

\section{A. Factors Affecting Participation}

There are many factors affecting community participation in the village development process. Factors classified as internal factors or abilities included gender, age, education level, income rate, and occupation. Participation of a man and that of a woman in development are different because of the established social system that differentiates the position between men and women. Such differences in position and degree will lead to differences in rights and duties between 
men and women, where men have a number of privileges compared to women. Thus, men will tend to contribute more [10]-[15].

Age is a factor that influences one's attitude towards the existing social activities. The middle-to-upper age group with moral attachment to the values and norms of the community which is more stable tends to have a higher level of participation than the other age groups [10], [15]-[18].

Good jobs and good income which support daily needs can encourage a person to participate in community activities [11], [14], [15], [18], [19].

Education is considered to affect the way one behaves towards his/her environment, an attitude necessary for improving the welfare of the whole community [10], [14], [16]-[19].

In addition to those internal factors, external factors also influence motivation to participate, for example economic motivation [10], [16], [20]-[23], political and leadership-related motivation [11], [21], [24], socio-cultural motivation [10], [20]-[23], [25], [26], knowledge-related motivation [10], [22] and motivation to participate which is influenced by norms or obedience to the existing rules ([23], [25], [26)].

\section{B. Bayesian Networks}

Bayesian networks [27] are a state-of-the-art model for reasoning under uncertainty in the machine learning field. They are especially useful in real-world problems composed by many different variables with a complex dependency structure. Examples of areas where these models have been successfully applied include genomics, text classification, automatic robot control, fault diagnostic, etc.

Every Bayesian network has a qualitative part and a quantitative part. The qualitative part (i.e., the structure of the Bayesian network) consists of a directed acyclic graph (DAG) where the nodes correspond to the variables in the domain problem and the edges between two variables correspond to direct probabilistic dependencies. On the other hand, the quantitative part consists of the specification of the conditional probability distributions that are stored in the nodes of the network [28].

DAG describes the relationship between attributes and consists of nodes and arcs, where each arc describes a probabilistic dependence. If an arc is drawn from A to B, then A serves as the parent or immediate predecessor of $B$ and $B$ serves as a descendant of A. The DAG illustration can be seen in Fig. 1.

In the illustration below, the arc displays the causal relationship-related information. For example, the node (attribute) $\mathrm{C}$ results either from the existence of the attribute $\mathrm{A}$ or not, and likewise, it may result either from the existence of the attribute B or not. It can be seen that the attribute D is independent of the attributes A and B. This implies that when the result of the attribute $\mathrm{C}$ is generated, attributes $\mathrm{A}$ and $\mathrm{B}$ do not provide additional information about whether the attribute D occurs or not.

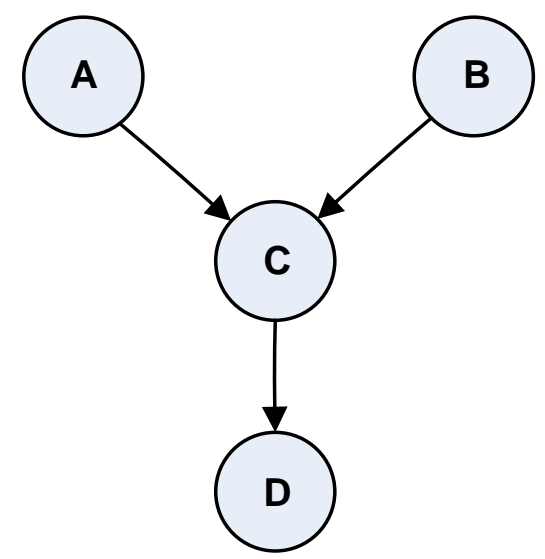

Fig. 1. Directed Acrylic Graph (DAG).

Suppose data $\mathrm{X}=\left(x_{1}, \ldots, x_{n}\right)$ are data with attributes $Y_{1}, \ldots$, $Y_{n}$. To calculate the possibility of a variable, (1) below is used:

$P\left(x_{1} \ldots x_{n}\right)=\prod_{i=1}^{\infty} P\left(x_{i} \mid \operatorname{Parents}\left(Y_{i}\right)\right.$

With:

$\mathrm{P}\left(\mathrm{x}_{1}, \ldots, \mathrm{x}_{\mathrm{n}}\right)=$ Probability base on attribute $\mathrm{x}_{1}, \ldots, \mathrm{x}_{\mathrm{n}}$

$\mathrm{n}=$ Number of attributes

$\mathrm{x}_{\mathrm{i}}=$ the ith data value

Parents $\left(Y_{i}\right)=$ Immediate predecessor or parent of the $Y_{i}$ attribute

For example, to calculate $\mathrm{P}(\mathrm{A}, \mathrm{B}, \mathrm{C}, \mathrm{D})$, then the probability is:

$$
\mathrm{P}(\mathrm{A}, \mathrm{B}, \mathrm{C}, \mathrm{D})=\mathrm{P}(\mathrm{A}) * \mathrm{P}(\mathrm{B} \mid \mathrm{A}) * \mathrm{P}(\mathrm{C} \mid \mathrm{A}, \mathrm{B}) * \mathrm{P}(\mathrm{D} \mid \mathrm{C})
$$

To calculate $\mathrm{P}$ (B | A), Bayes' theorem is used, which calculates the probability of an attribute based on a particular attribute. The formula of Bayes' theorem can be seen in (2):

$$
P(A \mid B)=\frac{P(B \mid A) P(A)}{P(B)}
$$

where:

$\begin{array}{ll}\mathrm{P}(\mathrm{A} \mid \mathrm{B}) & =\text { Probability A based on evidence B } \\ \mathrm{P}(\mathrm{B} \mid \mathrm{A}) & =\text { Probability B based on evidence A } \\ \mathrm{P}(\mathrm{A}) & =\text { Probability A } \\ \mathrm{P}(\mathrm{B}) & =\text { Probability } \mathrm{B}\end{array}$

\section{RESEARCH METHOD}

The method used in the weighting calculation (level of importance) of participation is using the Partial Least Square Path Modeling (PLS-PM) method and the Bayesian networks. The PLS-PM method is used to estimate the value of latent variables. The latent variable is a variable that cannot be measured directly and is measured through the indicator variable. In addition, PLS-PM is also used to examine the relationship structure of factors that influence participation built on expert opinion. Bayesian networks method is used to 
construct DAG structure and calculate the probability node (node probability) of each indicator variable.

1) Collect data using questionnaires on the participants of a particular community, which in this case the village community.

2) Then, identify parameters consisting of indicators in each of the factors affecting participation.

3) Afterwards, build a model illustrating the relationship between those factors affecting participation in the form of a Directed Acrylic Graph (DAG) structure of Bayesian networks. The initial DAG structure was developed based on experts' views derived from previous research and interviews with participants.

4) Estimate the score of latent variables and test the structure of the DAG model already built using PLS-PM. The test results will determine whether the constituent parameters of the model structure built will change or not.

5) The DAG model structure that already had a complete data set was then used as a model structure to calculate the Bayesian network inference using the complete data sets.

6) Calculate the probability of all node probability (NP) and the frequency (f) of showing up of each indicator of all factors.

Furthermore, results of the NP and f calculation were saved as 'a reference value' used as a guideline in the calculation of score for the participation interest of each participant. The calculation of participation scores was undertaken using two variables, namely NP and $\mathrm{f}$ of the indicators for each factor of participation. The score calculation for the participation interest of each participant was undertaken using (3), namely:

$$
W_{p}=\sum_{i=1}^{n}\left(N P_{i} * f_{i}\right)
$$

Where,

$\mathrm{W}_{\mathrm{p}}$ : weighted value of participant participation interest

$\mathrm{NP}_{\mathrm{i}}$ : the probability node value of the participant indicator

$\mathrm{f}_{\mathrm{i}} \quad$ : participant indicator frequency value

Where, $W_{p}$ refers to participation score, $N P$ refers to an indicator's node probability score of the indicator, and $f_{i}$ refers to an indicator's frequency score.

After the participation score had been obtained, score normalization was undertaken. Normalization is a technique to standardize or make the data range equal, thus no attribute is too dominant over the other attributes. The normalization process was undertaken using (4), namely:

$$
W_{p_{\text {normalizaion }}}=\frac{w_{p}-w_{p_{\min }}}{w_{p_{\text {makx }}}-w_{p_{\min }}}
$$

The participation score that had undergone normalization was then used in the calculation to determine the proposed village development programs taking priority.

\section{EXPERIMENT}

\section{A. Establishing the Structure for the Relationship between Factors Affecting Participation}

This study used questionnaire data from 130 participants, consisting of 3 latent variables and 13 manifest variables (indicators). Parameters identified in the study are divided into two types of parameters, namely internal parameters (ability) and external parameters (motivation). Internal parameters are: gender, age, education, occupation, income, while external parameters are: economic, political, socio-cultural, norms and knowledge motivation. In addition, there are also three parameters that directly affect the level of participation, they are: attendance meetings (meeting), give suggestions (proposal), and involvement in providing decisions (decision).

The first step was to the structure for the relationship between factors affecting participation based on experts' views as illustrated in Fig. 2.

Afterwards, the model illustrating the structure of the relationship between the factors influencing participation was tested using PLS-PM.

The Outer evaluation of this model specifies the relationship between latent variables and their indicators. or it can be said that the outer model defines how each manifest variable (indicator) corresponds to its latent variable. Test on outer model for formative indicator that is:

- Significance of weights. The weight value of the formative indicator with its construct should be significant.

- Multicolliniearity. Multicolliniearity test is done to know the relationship between indicators. To find out if the formative indicator is having multicolliniearity by knowing the VIF value. VIF values between 5 to 10 can be said that the indicator occurs multicolliniearity.

The test result shows that weigth value almost all indicator variables produce significant weight value, that is not less than 0,1 , that is allowed limit value [29]. Only one indicator variable whose value is less than 0.1 is a gender variable with a value of 0.048 , so the gender variable can be excluded from the model. The result of coefficient path test can be seen in Fig. 3.

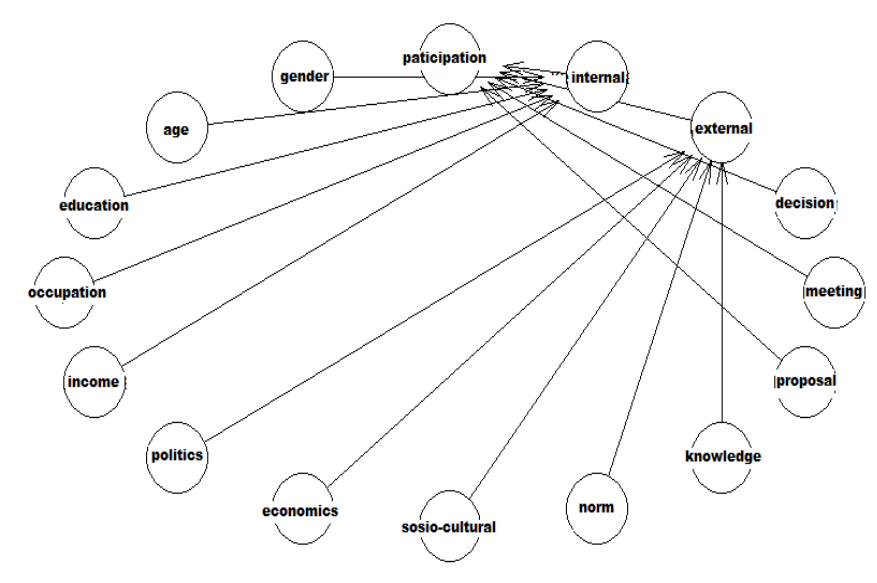

Fig. 2. The model of the relationship structure of factors of participation. 


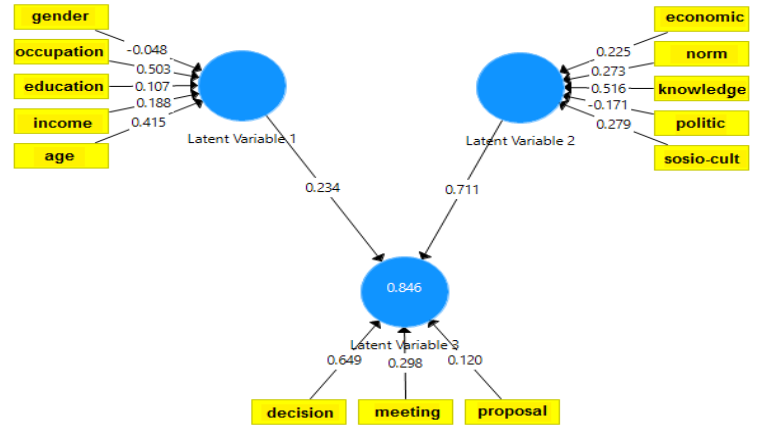

Fig. 3. Outer weight factors of participation.

The manifest variable in a formative block must be tested for its multicollinearity. Multicollinearity testing among indicators in a formative block uses the value of variance inflation factor (VIF). If a VIF value of $>10$ occurs in the form of collinierity between the indicators in one such formative block [30]. Test results show all VIF indicator values less than 10 (Fig. 3), so it can be concluded that there is no collinierity between indicators.

After assessing quality of the measurement model, the next step was to assess the structure. To examine results of each regression in a structural equation, it is necessary to display the results contained in the inner model. In addition to the results of the regression equation, quality of the structural model was evaluated by examining three quality indexes or matrices, namely the coefficient of determination $R^{2}$.

The coefficient of determination $R^{2}$ is the coefficient of determination of endogenous latent variables. For each regression in the structural model, the matrix $R^{2}$ was used which was interpreted in the same way as in the multiple regression analysis. $R^{2}$ indicates the number of variances an endogenous latent variable has which is described by its independent latent variable. The $R^{2}$ value generated in this research is equal to 0.849 .

\section{B. Calculating the NP and Frequency of Each Indicator}

Results of the testing using data obtained from questionnaires show that the factors of gender has no significant correlation so that the DAG structure used in inference calculation involved 12 indicators only. Afterwards, a DAG structure was developed based on the data set obtained from the testing results and PLS estimation (latent variables) undertaken. The DAG structure was built using expert approach as shown in Fig. 4.

The DAG structure (Fig. 4), illustrates a graphical representation and a combination of probability $\mathrm{P}$ (age, education, occupation, income, politics, economy, socioculture, norms, knowledge, proposals, meetings, decisions, motivation, abilities, and participation) that can be factored as a set of conditional independence relations expressed as follows (1):

$P(A g, E d, O c, I n c, P o, E c, S o, N, K n, P r, M e, D e, M o, A b$, $P a)=P(A g, E d, O c, I n c, P o, E c, S o, N, K n, P r, M e, D e, M o$, $A b, P a)=P(A g)(E d)(O c),(I n c),(P o)(E c)(S o)(N)(K n)(P r)$ (Me) (De) (Int $\mid A g, E d, O c, I n c)(E x t \mid P o, E c, S o, N, K n)$ $(\mathrm{Pa} \mid$ Int,Ext)

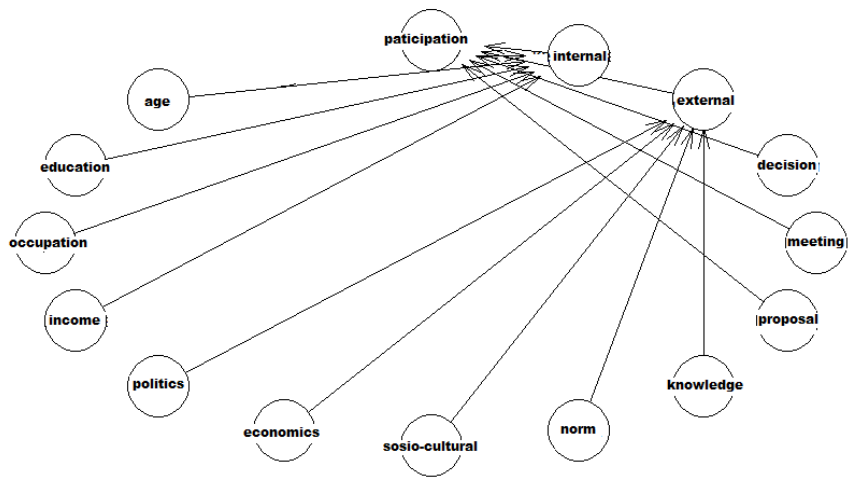

Fig. 4. DAG structure of factors of participation.

Where,

$\mathrm{Ag}=$ Age, $\mathrm{Ed}=$ Education, Oc = Occupation, Inc = Income, $\mathrm{Po}=$ Politics, $\mathrm{Ec}=$ Economics, $\mathrm{So}=$ Socio-culture, $\mathrm{N}$ $=$ Norm, $\mathrm{Kn}=$ Knowledges, $\mathrm{Pr}=$ Proposals, $\mathrm{Me}=$ Meetings, De $=$ Decision, Int $=$ Internal, Ext $=$ External, $\mathrm{Pa}=$ Participation

Based on Fig. 4, it can be seen that 12 (twelve) nodes are nodes with a conditional independence relation. Those twelve nodes are age, education, occupation, income, politics, economy, socio-culture, norms, knowledge, proposals, meetings, and decisions. The score of each node can be calculated based on its indicator, which in this research is called node probability (NP). The following is an example of the calculation of the node age with age between 18 to 40 years as the indicator, where the NP is calculated as follows:

$\mathrm{P}(\mathrm{Ag}=18-40)=\mathrm{P}(\mathrm{Ag}=18-40, \mathrm{Ed}, \mathrm{Oc}, \mathrm{Inc}, \mathrm{Po}, \mathrm{Ec}, \mathrm{So}, \mathrm{N}$, $\mathrm{Kn}, \mathrm{Pr}, \mathrm{Me}, \mathrm{De}$, Int, Ext, Pa)

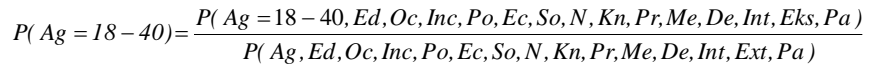

The prior probability score or the confidence value of the participation variable is the resulting score to explain the level of confidence of each participation variable. Furthermore, inference Bayesian networks with DAG structure built based on data that has been tested and estimated using PLS. Probability inference in Bayesian network was calculated so as to determine the Node Probability (NP) and the probability of showing up/ frequency (f) of each indicator as shown in Table 1, which were then used as a guideline in the calculation of the score of participation interests of the participants.

TABLE I. CALCULATION RESULTS OF NP AND FREQUENCY SCORES OF EACH INDICATOR

\begin{tabular}{|l|l|l|l|l|}
\hline Variable & Indicator & $\boldsymbol{N P}$ & $\boldsymbol{f}$ & $\boldsymbol{N P} \boldsymbol{f}$ \\
\hline age & 1 & 0.0422 & 0.31 & 0.0131 \\
\hline age & 3 & 0.3879 & 0.39 & 0.1513 \\
\hline age & 2 & 0.5655 & 0.3 & 0.1697 \\
\hline education & 2 & 0.0803 & 0.06 & 0.0048 \\
\hline education & 4 & 0.5330 & 0.22 & 0.1173 \\
\hline education & 5 & 0.3339 & 0.16 & 0.0534 \\
\hline education & 1 & 0.0001 & 0.34 & 0.0000 \\
\hline education & 3 & 0.0457 & 0.22 & 0.0101 \\
\hline occupation & 2 & 0.0221 & 0.04 & 0.0009 \\
\hline occupation & 4 & 0.1676 & 0.24 & 0.0402 \\
\hline
\end{tabular}




\begin{tabular}{|c|c|c|c|c|}
\hline Variable & Indicator & $N P$ & $f$ & $N P * f$ \\
\hline occupation & 5 & 0.7675 & 0.14 & 0.1075 \\
\hline occupation & 1 & 0.0000 & 0.17 & 0.0000 \\
\hline occupation & 3 & 0.0337 & 0.41 & 0.0138 \\
\hline icome & 1 & 0.1219 & 0.22 & 0.0268 \\
\hline icome & 3 & 0.1071 & 0.27 & 0.0289 \\
\hline icome & 2 & 0.3103 & 0.12 & 0.0372 \\
\hline icome & 4 & 0.4285 & 0.34 & 0.1457 \\
\hline icome & 5 & 0.0296 & 0.05 & 0.0015 \\
\hline politic & 3 & 0.0495 & 0.03 & 0.0015 \\
\hline politic & 5 & 0.6938 & 0.16 & 0.1110 \\
\hline politic & 2 & 0.0709 & 0.24 & 0.0170 \\
\hline politic & 4 & 0.1798 & 0.16 & 0.0288 \\
\hline politic & 1 & 0.0000 & 0.41 & 0.0000 \\
\hline economics & 3 & 0.0414 & 0.04 & 0.0017 \\
\hline economics & 2 & 0.0836 & 0.16 & 0.0134 \\
\hline economics & 4 & 0.7379 & 0.18 & 0.1328 \\
\hline economics & 5 & 0.1430 & 0.44 & 0.0629 \\
\hline economics & 1 & 0.0000 & 0.18 & 0.0000 \\
\hline socio-culture & 2 & 0.0660 & 0.04 & 0.0026 \\
\hline socio-culture & 4 & 0.6012 & 0.24 & 0.1443 \\
\hline socio-culture & 5 & 0.2693 & 0.17 & 0.0458 \\
\hline socio-culture & 1 & 0.0000 & 0.34 & 0.0000 \\
\hline socio-culture & 3 & 0.0620 & 0.21 & 0.0130 \\
\hline norm & 2 & 0.0138 & 0.03 & 0.0004 \\
\hline norm & 4 & 0.1875 & 0.26 & 0.0487 \\
\hline norm & 5 & 0.7439 & 0.16 & 0.1190 \\
\hline norm & 3 & 0.0507 & 0.15 & 0.0076 \\
\hline norm & 1 & 0.0000 & 0.4 & 0.0000 \\
\hline knowledges & 1 & 0.0015 & 0.16 & 0.0002 \\
\hline knowledges & 3 & 0.0869 & 0.15 & 0.0130 \\
\hline knowledges & 2 & 0.0012 & 0.12 & 0.0001 \\
\hline knowledges & 5 & 0.1220 & 0.44 & 0.0537 \\
\hline knowledges & 4 & 0.7876 & 0.13 & 0.1024 \\
\hline proposal & 2 & 0.0000 & 0.05 & 0.0000 \\
\hline proposal & 1 & 0.0000 & 0.16 & 0.0000 \\
\hline proposal & 4 & 0.8077 & 0.15 & 0.1212 \\
\hline proposal & 3 & 0.0688 & 0.51 & 0.0351 \\
\hline proposal & 5 & 0.1148 & 0.13 & 0.0149 \\
\hline meeting & 1 & 0.0000 & 0.12 & 0.0000 \\
\hline meeting & 3 & 0.1491 & 0.13 & 0.0194 \\
\hline meeting & 5 & 0.3833 & 0.16 & 0.0613 \\
\hline meeting & 2 & 0.0000 & 0.32 & 0.0000 \\
\hline meeting & 4 & 0.4740 & 0.27 & 0.1280 \\
\hline decision & 1 & 0.0000 & 0.2 & 0.0000 \\
\hline decision & 3 & 0.1119 & 0.12 & 0.0134 \\
\hline decision & 5 & 0.0723 & 0.16 & 0.0116 \\
\hline decision & 2 & 0.0000 & 0.4 & 0.0000 \\
\hline decision & 4 & 0.8098 & 0.12 & 0.0972 \\
\hline
\end{tabular}

\section{Calculating the Participation Score of the Participants}

The example of the data on the indicators of the factors of proposal makers' participation with the input data for Proposal Maker $l\left(P_{I}\right)$ is presented in Table 2 . The participation score was calculated by referring to the "data reference" of the NP and frequency scores generated from the calculation in Table 1.

The example calculation of the participation interest score used (3), using the indicators of participation factors $P_{1}$ in Table 2 adjusted to the NP and $\mathrm{f}$ scores in Table 1 , the participation score $\left(W_{p}\right)$ can be calculated.

$W_{p 1}=\left\{(N P * f)_{\text {age }}+(N P * f)_{\text {occupation }}+(N P * f)_{\text {education }}+\right.$ $(N P * f)_{\text {income }}+(N P * f)_{\text {politic }}+(N P * f)_{\text {economics }}+(N P * f)_{\text {sosio- }}$ cultural $+(N P * f)_{\text {norm }}+(N P * f)_{\text {knowledges }}+(k * f)_{\text {proposal }}+(N P *$ $\left.f)_{\text {meeting }}+(N P * f)_{\text {decision }}\right\}=0.4209$
TABLE II. INDICATORS FOR THE FACTORS OF PARTICIPATION P1

\begin{tabular}{|l|l|l|}
\hline $\begin{array}{l}\text { Factors of } \\
\text { Participation }\end{array}$ & Indicators & NP*f \\
\hline age & $18-40$ years old (1) & 0.0131 \\
\hline occupation & Labour (2) & 0.0009 \\
\hline education & Junior high school (2) & 0.0048 \\
\hline income & 1 & 0.0268 \\
\hline politic & 2 & 0.0170 \\
\hline economics & 5 & 0.0629 \\
\hline sosio-cultural & 4 & 0.1443 \\
\hline norm & 4 & 0.0487 \\
\hline knowledges & 4 & 0.1024 \\
\hline proposal & 1 & 0 \\
\hline meeting & 2 & 0 \\
\hline decision & 1 & 0 \\
\hline
\end{tabular}

TABLE III. MULTIPLICATION VALUE OF NP AND HighEST AND LOWEST FREQUENCY

\begin{tabular}{|l|l|l|}
\hline variable & $(\boldsymbol{N P} * f)_{\min }$ & $(\boldsymbol{N P} * f)_{\max }$ \\
\hline age & 0.0201 & 0.1591 \\
\hline occupation & 0.0043 & 0.0987 \\
\hline education & 0.0014 & 0.0725 \\
\hline income & 0.0038 & 0.1517 \\
\hline politic & 0.0026 & 0.0857 \\
\hline economics & 0.0015 & 0.1074 \\
\hline sosio-cultural & 0.0028 & 0.1051 \\
\hline norm & 0.0025 & 0.0808 \\
\hline knowledges & 0.0013 & 0.0881 \\
\hline proposal & 0.0000 & 0.1040 \\
\hline meeting & 0.0000 & 0.1220 \\
\hline decision & 0.0000 & 0.0774 \\
\hline
\end{tabular}

1) Score normalization

The normalization process was done by calculating the highest participation score $W_{p \max }$ using (5) and the lowest participation score $W_{p \min }$ using (6). The data on the lowest and highest NP and frequency scores can be seen in Table 3. $W_{p \max }$ can be calculated by multiplying the NP by the frequency of each indicator with the highest score. Conversely, $W_{p \text { min }}$ can be calculated by multiplying the $\mathrm{Np}$ by the frequency of each indicator with the lowest score.

$$
\begin{aligned}
& W_{\text {pmin }}=\sum_{\text {indicatormin }=1}^{n}(N P \times f) \\
& W_{\text {pmax }} x=\sum_{\text {indicatormin }}^{n}(N P \times f)
\end{aligned}
$$

The calculation of the lowest participation score using (5) is described as follows:

$W_{p \min }=\left\{(N P * f)_{\text {age } \min }+(N P * f)_{\text {occupation min }}+(N P *\right.$ $f)_{\text {education min }}+(N P * f)_{\text {income min }}+(N P * f)_{\text {politic min }}+(N P *$ $f)_{\text {economics } \min }+(N P * f)_{\text {sosio-culuturalmin }}+(N P * f)_{\text {norm min }}+(N P *$ $f)_{\text {knowledge min }}+(N P * f)_{\text {proposal min }}+(N P * f)_{\text {meeting min }}+(N P * f)_{\text {decision }}$ $\min \} \quad=0.2615$

The calculation of the highest participation score using (6) is described as follows:

$$
W_{p \max }=\left\{(N P * f)_{\text {age } \max }+(N P * f)_{\text {occupation } \max }+(N P *\right.
$$
f) education $\max +(N P * f)_{\text {income } \max }+(N P * f)_{\text {politic } \max }+(N P *$ $f)_{\text {economics } \max }+\left(N P^{*} f\right)_{\text {sosio-culutural max }}+(N P * f)_{\text {norm } \max }+(N P *$ 
$f)_{\text {knowledge } \max }+\left(N P^{*} f\right)_{\text {proposal max }}+(N P * f)_{\text {meeting } \max }+(N P *$ $\left.f)_{\text {decision max }}\right\}=1.5322$

Furthermore, normalization was calculated using (4). Thus, the normalized $W_{p l}$ is equal to

$$
W_{\text {pnormalizaion }}=0.12
$$

The calculation results for the score of proposal makers' participation interest $\left(W_{p 1}\right)$ that had undergone normalization to equal to 0.12 , which is the score of participation interest for the first proposal maker $\left(W_{p l}\right)$. In the same way, the score of participation interest for the subsequent proposal maker can also be calculated.

The score of participation interest for the subsequent proposal maker $\left(W_{p l}\right)$ was used to calculate the score of DM's preference in relation to the alternatives according to the alternatives proposed by each proposal maker.

The score of participation interest for the subsequent proposal maker $\left(W_{p 1}\right)$ can be used to determine the ranking of decisions relating to village development planning programs. The $W_{p}$ calculation results were then tested by applying them to the current decision-making model.

2) Implementation of participation scores in multiplecriteria decision making

The current decision-making model relating to determination of proposed village development programs taking priority involves many criteria and decision makers. Those decision makers consist of several people, ranging from 7 to 11 persons, and commonly are referred to as the team of 7 or 11 persons. These teams are considered as representatives of all stakeholders in the village. All decision makers use the same criteria in making a decision, namely felt by many people (C1), extremely serious (C2), better income (C3), the number of occurrences (C4), potential support resources (C5). Such criteria are used to assess programs proposed by the community. To help illustrate a problem, the attributes of the problem can be represented by the following notations:

a) $\mathrm{DM}=\left\{\mathrm{dm}_{1}, \ldots \mathrm{dm}_{\mathrm{n}}\right\}$ refers to decision makers, i.e. the persons who will make decisions

b) $\mathrm{A}=\left\{\mathrm{a}_{1}, \ldots \mathrm{a}_{\mathrm{n}}\right\}$ with $\mathrm{n} \geq 2$, refers to a program proposed by the community, which is a group of alternatives to be ranked.

c) $\mathrm{C}=\left\{\mathrm{c}_{1}, \ldots \mathrm{c}_{\mathrm{n}}\right\}$ with $\mathrm{n} \geq 2$, refers to a group of criteria, i.e. the criteria taken into account in the decision-making process.

d) $\mathrm{T}=\left\{\mathrm{t}_{1}, \ldots \mathrm{t}_{\mathrm{n}}\right\}$ refers to the final goal, which is the resulting ranking in the form of a sequence of alternatives decided by decision makers.

The hierarchy of the decision making relating to determination of proposed village development programs taking priority is illustrated in Fig. 5.

In the decision-making process with a hierarchy as shown in Fig. 5, decision makers use the same criteria without considering the score of each criterion.

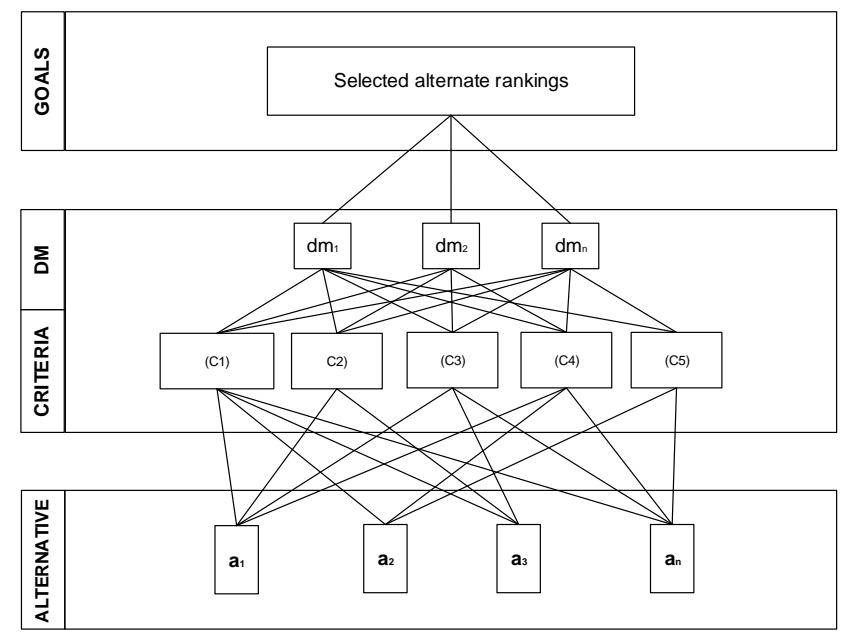

Fig. 5. Hierarchy of decision-making.

The data used to test the proposed model consisted of data of nine decision makers, namely $\mathrm{dm}_{1} . . \mathrm{dm}_{9}$ and were associated with factors influencing participation. The data on proposed programs (a) data consisted of 10 proposals, namely, $a_{1}, . . a_{10}$, where each alternative had its own score for participation of proposal makers $\left(W_{p}\right)$. The data on the scores for participation of proposal makers used are presented below:

$W_{p 1}\left(a_{1}\right)=0.12 ; W_{p 2}\left(a_{2}\right)=0.18 ; W_{p 3}\left(a_{3}\right)=0.29 ; W_{p 4}\left(a_{4}\right)=0.23 ; W$ ${ }_{p 5}\left(a_{5}\right)=0.45 ; W_{p 6}\left(a_{6}\right)=0.45 ; W_{p 7}\left(a_{7}\right)=0.49 ; W_{p 8}\left(a_{8}\right)=0.48 ; W_{p 9}\left(a_{9}\right)$ $=0.34 ; W_{p 10}\left(a_{10}\right)=0.45$

Each criterion has the same score and thus the total participation score $\left(T_{\text {model }}\right)$ was calculated by multiplying each participation score $W_{p}$ by the total initial score $\left(T_{\text {initial }}\right)$, (7) as follows:

$$
T_{\text {model }}=T_{\text {initial }} * W_{p}
$$

Results of the score calculation using the participation score $\left(T_{\text {model }}\right)$ was compared with program realization as shown in Table 4.

Afterwards, testing was done using a confusion matrix to calculate accuracy, precision, and recall. Results of the calculation are presented in Table 4 and summarized in Table 5.

Calculation of the confusion matrix is described as follows:

$$
\begin{aligned}
\text { Accuracy } & =\frac{T P+T N}{T P+T N+F P+F N} \times 100 \% \\
& =50 \% \\
\text { Precision } & =\frac{T P}{T P+F P} \times 100 \% \\
& =80 \% \\
\text { Recall }= & \frac{T P}{T P+F N} \times 100 \% \\
& =50 \%
\end{aligned}
$$


TABle IV. The Results of The CALCUlation of the SCORE With the Weighted VAlue of Participation

\begin{tabular}{|c|c|c|c|c|c|c|c|c|c|c|c|}
\hline \multirow{2}{*}{$\begin{array}{l}\text { ID. } \\
\text { Alternative }\end{array}$} & \multicolumn{5}{|c|}{ Criteria and score } & \multirow{2}{*}{$\begin{array}{l}\text { Score Total } \\
(T)\end{array}$} & \multirow{2}{*}{$\begin{array}{l}\text { The weight of } \\
\text { participation }(W p)\end{array}$} & \multirow{2}{*}{$\begin{array}{l}\text { Score Total of } \\
\text { model }\left(T_{\text {model }}\right)\end{array}$} & \multirow{2}{*}{$\begin{array}{l}\text { Initial } \\
\text { rank }\end{array}$} & \multirow{2}{*}{$\begin{array}{l}\text { model } \\
\text { rank }\end{array}$} & \multirow{2}{*}{$\begin{array}{l}\text { Actua } \\
\text { (2015) }\end{array}$} \\
\hline & C1 & C2 & C3 & $\mathrm{C4}$ & C5 & & & & & & \\
\hline$a_{1}$ & 77 & 72 & 75 & 76 & 79 & 379 & 0.12 & 45.48 & 1 & $7(\mathrm{~N})$ & $\mathrm{Y}$ \\
\hline $\mathrm{a}_{2}$ & 78 & 77 & 76 & 73 & 74 & 378 & 0.18 & 68.04 & 2 & $5(\mathrm{Y})$ & $\mathrm{Y}$ \\
\hline$a_{3}$ & 78 & 70 & 76 & 76 & 77 & 377 & 0.29 & 109.33 & 3 & $8(\mathrm{~N})$ & $\mathrm{N}$ \\
\hline$a_{4}$ & 78 & 78 & 67 & 76 & 77 & 376 & 0.23 & 86.48 & 4 & $4(\mathrm{Y})$ & $\mathrm{Y}$ \\
\hline $\mathrm{a}_{5}$ & 78 & 75 & 76 & 67 & 77 & 373 & 0.45 & 167.85 & 5 & $2(\mathrm{Y})$ & $\mathrm{Y}$ \\
\hline$a_{6}$ & 79 & 76 & 76 & 70 & 70 & 371 & 0.45 & 166.95 & 6 & $1(\mathrm{Y})$ & $\mathrm{N}$ \\
\hline $\mathrm{a}_{7}$ & 77 & 75 & 75 & 71 & 72 & 370 & 0.49 & 181.3 & 7 & $10(\mathrm{~N})$ & $\mathrm{N}$ \\
\hline $\mathrm{a}_{8}$ & 66 & 67 & 76 & 79 & 81 & 369 & 0.48 & 177.12 & 8 & $6(\mathrm{~N})$ & $\mathrm{N}$ \\
\hline $\mathrm{a}_{9}$ & 77 & 75 & 76 & 69 & 70 & 367 & 0.34 & 124.78 & 9 & $9(\mathrm{~N})$ & $\mathrm{N}$ \\
\hline$a_{10}$ & 79 & 77 & 69 & 81 & 59 & 365 & 0.45 & 164.25 & 10 & $3(\mathrm{Y})$ & $\mathrm{Y}$ \\
\hline
\end{tabular}

TABLE V. CONFUSION MATRIX TABLE

\begin{tabular}{|l|l|l|}
\hline \multirow{2}{*}{ Prediction } & Actual \\
\cline { 2 - 3 } & Positif & Negatif \\
\hline True & 4 & 1 \\
\hline False & 1 & 4 \\
\hline
\end{tabular}

A model is deemed good if it has high precision and recall values. Results of the test calculation using a confusion matrix generated scores for recall, precision, and accuracy by $50 \%$, $80 \%$, and $50 \%$, respectively. These results are not too ideal for a model because the decision to realize a program within the government does not only depend on whether the program will facilitate development or not but also on the various interests other than objectives of the development.

\section{CONCLUSION}

Research conclusions are presented as follows:

1) Community participation in development planning programs is influenced by the factors of interests of the respective participants. The model structure of the relationship between those participation factors can be constructed using the PLS-PM approach with latent variables

2) The interest factors affecting participation can be quantified in the form of a participation score. This participation score can be calculated using the DAG structure and inferred from Bayesian networks, namely the calculation of probability nodes and the cumulative frequency of each indicator.

3) The participation interest score can be used to represent participants' interests with regard to decision making. In the case of for decision making priority determination of proposed program for village development program, the confusion matrix testing generates accuracy by 0.5 , precision by 0.8 , and recall by 0.5 .

\section{REFERENCES}

[1] V.Luyet, R. Schlaepfer, M.B. Parlange, A. Buttler, "A framework to implement Stakeholder participation in environmental projects, Journal of Environmental Management 111, 2012

[2] H. Hoshino, N. Zhong, "Dynamic Hybrid Type Mining in an Intelligent E-Government Model". IEEE/WIC/ACM International Conferences on Web Intelligence and Intelligent Agent Technology - Workshops, 2007

[3] P.A. Sabatier, A. Vedlitz, W. Foch, M. Lubell, M. Matlock, "Swimming Upstream: Collaborative Approaches to Watershed Management. In: American and Comparative Environmental Policy". MIT Press, 328 pp. 2005.
[4] D.S., Kenney, S.T., McAllister, W.H., Caile, J.S., Peckham, "The New Watershed. Source Book: a Directory and Review of Watershed Initiatives in the Western United States". Natural Resources Law Center, University of Colorado School of Law. 2000.

[5] G.A., Wilson, "The Australian Landcare movement: towards 'postproductivist' rural governance?" Journal of Rural Studies 20 (4), 461e484. 2004

[6] S. Rist, M. Chidambaranathan, C. Escobar, U.Wiesmann, A. Zimmermann, "Moving from sustainable management to sustainable governance of natural resources: the role of social learning processes in rural India, Bolivia and Mali”. Journal of Rural Studies 23 (1), 219e237. 2007,

[7] J. Carter, J. Gronow, "Recent experience in collaborative forest management: a review paper". CIFOR Occasional paper No.43, CIFOR, Bogar, Indonesia. 48 pp. 2005.

[8] M. Buchecker, M. Hunziker, F. Kienast, "Participatory landscape develop- ment: overcoming social barriers to public involvement". Landscape and Urban Planning 64, 29e47. 2003.

[9] Conyers, Diana. "An Introduction to Social Planning in The Third Wordl", By John Wiley \& Sons Ltd. 1991.

[10] E.K. Yiridoe, D.O.A. Atari, R. Gordon, S. Smale, "Factors influencing participation in the Nova Scotia environmental farm plan program”. Land Use Policy, 27(4), pp.1097-1106, 2010.

[11] A. Nahayo, M.O. Omondi, X.H. Zhang, L.Q. Li, G.X. Pan, S. Joseph, Factors influencing farmers' participation in crop intensification program in Rwanda. Journal of Integrative Agriculture, 16(6), pp.1406-1416, 2017.

[12] E.D,Lioutas, I. Tzimitra-Kalogianni, C. Charatsari, ”Small ruminant producers' training needs and factors discouraging participation in agricultural education/training programs". Livestock Research for Rural Development, 22, 126, 2010.

[13] C.Charatsari, A. Papadaki-Klavdianou, A. Michailidis, M. Partalidou. "Great expectations? Antecedents of women farmers' willingness to participate in agricultural education programs". Outlook on Agriculture, 42, 193-199, 2013.

[14] F. Dolisca, D.R. Carter, J.M. McDaniel, D.A. Shannon, C.M. Jolly, "Factors influencing farmers' participation in forestry management programs: A case study from Haiti”. Forest ecology and management, 236(2), pp.324-331, 2006.

[15] K.K.S. Nxumalo, O.I. Oladele, "Factors affecting farmers' participation in agricultural programme in zululand district, kwazulu natal province, South Africa". Journal of Social Science, 34, 83-88, 2013.

[16] K.Stone, M.Bhat, R.Bhatta, A.Mathews, "Factors influencing community participation in mangroves restoration: A contingent valuation analysis". Ocean \& Coastal Management, 51(6), pp.476-484, 2008.

[17] E. Defrancesco, P. Gatto, F. Runge, S. Trestini, "Factors affecting farmers' participation in agri-environmental measures: evidence from a case study". In10th Joint Conference on Food, Agriculture and the Environment, Duluth, Minnesota, August 2006 Aug 27 (pp. 27-30).

[18] D. Bertoni, and A. Olper, "The political economy of agri-environmental measures: an empirical assessment at the EU regional 
level". APSTRACT: Applied Studies in Agribusiness and Commerce, 6(3-4), pp.71-82, 2012.

[19] S. Najafi, "Investigation of factors affecting villagers' social and economic participation in rural construction and development programs (Case study: Sarbishe city)". Agric. sci. dev., Vol(3), No (9), September. pp. 296-301, 2014,

[20] Hosseini, "Analysis of Factors Affecting Sustainable Urban Development with Emphasis on Citizen Participation" GUGEF Vol. 04, No.02 May 2015.

[21] PK. Macharia, L.Wambua, J. Mwangulu, "A Study To Assess The Influence Of Citizen Participation On Decentralized Service Delivery, A Case Study Of Kipipiri Constituency, Nyandarua County". International Journal of Social Sciences Management and Entrepreneurship. 2014;1(2):85-105.

[22] A. Drazkiewicz, E. Challies, J. Newig. "Public participation and local environmental planning: Testing factors influencing decision quality and implementation in four case studies from Germany". Land Use Policy, 46, pp.211-222, 2015

[23] J. Straka, M. Tuzová, "Factors Affecting Development of Rural Areas in the Czech Republic: A Literature Review". Procedia-Social and Behavioral Sciences, 220, pp.496-505, 2016.

[24] E.D, Lioutas, I. Tzimitra-Kalogianni, C. Charatsari. "Small ruminant producers' training needs and factors discouraging participation in agricultural education/training programs" Livestock Research for Rural Development, 22, 126, 2010.

[25] K.G. Nejad, A. Fatehi Dehaghani. "Investigate fields and sociological factors affecting social participation among villagers (construction project of irrigation and drainage network for agricultural land in the right bank of the Jarrahi River, the village's case study of city functions Ramshir)". Journal, Humanities and Social Sciences, June 2015 Vol 8 (6) 126-147

[26] M.S.H. Swapan. "Who participates and who doesn't? Adapting community participation model for developing countries". Cities, 53, pp.70-77, 2016.

[27] J. Pearl. "Probabilistic Reasoning with Intelligent Systems", Morgan \& Kaufman, San Mateo, 1988.

[28] A.R. Masegosa, S. Moral, "An interactive approach for Bayesian network learning using domain/expert knowledge". International Journal of Approximate Reasoning, 54(8), pp.1168-1181, 2013.

[29] M.L. Sawatsky, M. Clyde, F. Meek, Partial least squares regression in the social sciences. The Quantitative Methods for Psychology, 11 (2), $52-62,2015$,

[30] G. Sanchez, "PLS Path Modeling with R" Trowchez Editions. Berkeley, 2013. 